\title{
MENYIKAPI BUDAYA KEKERASAN
}

\section{Oleh Zaenul Mahmudi}

Terminal Kampung Rambutan Jakarta Timur seakan menjadi saksi bisu atas terpangganonyal empat sekawanan pencopet. Kisah ini bermula clari tertangkaptangannya seorang pencopet yang sengaja menjarah mangsanyal, "copeeeet" teriak korban yang kedapatan tasnya dijarahalh, kontan saja semua mata dari beratus orang tertuju kepada sumber suara. Massa yang telah lama memendam rasa benci dan dendam yang menclalam atas praktek pencopetan yang pada akhir-akhir ini sangat merajalela, terutama di Terminal Kampung Rambutan seakan mendapatkan "roti" untuk melampiaskan dendamnya, bak a pi (dendam) yang disiram dengan bensin. Dari sumber suara tersebut massa melihat seseorang yang diikuti tiga orang temannyal lari tunggang langgang ke sebuah Metromini, massa langsung menyimpulkan bahwa merekalah pencopetnya, massa langsung mengejar ke arah Metromini tersebut, "bakar itu Metromini" teriak salah seorang massa. "Jangan, kita paksal turun mereka". Akhirnya komplotan pencopet dipaksal turun dan dibakartah mereka hiclup-hidup. Oh... Astagbfirullab wa Inna Lillabi wa Inna Ilaibi Raji'un.

Ini adalah salah satu contoh fenomena kekerasan yang dilakukan massa, masih banyak lagi kekerasan yang melanda seperti di Maluku, kekerasan dengan mengatasnamakan agama, pembantaian massaatas nama pembangunan seperti di waaluk Kedung Ombo, Boyolali, Jawa Tengah, Kasus Nipah di Madura clan lain sebagainya; dan pembantaian atas nama ketertiban, seperti perebutan Kantor Pimpinan Pusat PDI Jakarta pada tahun 1996 yang dikenal dengan peristiwa 27 Juli, semua bentuk kekerasan ini memakan korban yang cukup banyak, dan masih menyisakan kesedihan yang mendalam bagi para ahli waris clan keluarga korban. Suclah sebegitukah kejam dikau wahai Bangsaku? melegalkan pembantaian rakyat atas nama yang terlalu mulya untuk cligunakan, meletakkan sesuatu dengan cara yang terbalik, Orang Barat sana bilang "Put the cart before the borse"(AS Hornby, 1986: 124).

\section{Tinjauan Definisi}

Demi memperoleh gambaran yang lebih jelas atau agar kita terhindar clari kekaburan masal ah, salya akan mencermati keyuordnya, yaitu kata budaya dan kekerasan. Budaya atau kebudayaan berasal clari bahasaa Sanskerta "buddbayab", suatu bentuk jamak dari kata "buddbi" yang berarti budi atau akal, sehingga kebudayaan bisa diàrtikan clengan hal-hal yang berkaitan clengan budi atau akal. Sedangkan istilah "culture" yang searti clengan kebudayaan berasal dari bahasa Latin "colere" yang berarti mengolah atau mengerjakan, sehingga kebudayaan (culture) bisa diartikan dengan segala daya dan kegiatan manusia untuk mengolah dan mengubah alam (Koentjaraningrat, 1965 : 77-78).

Sedangkan menurut sallah seorang Antropolog, E.B. Taylor yang dikutip oleh Soerdjono Soekanto (1974 : 40) "Kebudayaan adalah kompleks yang mencakup pengetahuan, kesenian, moral, kemampuan-kemampuan dan kebiasaan-kebiasaan lain yang clilakukan manusia sebagai anggota masyarkat. Dan masih banyak lagi definisi-clefinisi kebudayaan yang dikemukakan oleh para pakar di biclangnya yang tidak disebutkan disini, namun clari definisi-definisi tersebut dapat ditarik benang merah bahwa unsur-unsur kebudayaan meliputi :

1. Kebudayaan terwujud dan tersalurkan dari perilaku manusia

2. Kebudayaan telah lahir terlebilh dahulu sebelum suatu generasi tertentu lahir clan tidak akan sirna 
clengan matinya generasi tersebut

3. Kebudayaan cliperlukan manusia dan diwujudkan clalam tingkah lakunya

4. Kebuclayaan berisi aturan-aturan yang meliputi kewajiban-kewajiban dan tinclakan-tinclakan, baik yang diterima maupun yang clitolak atau yang dilarang maupun yang diizinkan (Soekanto, 1974:48).

Seclangkan "kekerasan" clalam Kamus Besar Bahasa Indonesia (1996 : 485) disebutkan sebagai perbuatan seseorang atau kelompok orang yang menyebabkan ceclera atau matinya orang lain atau menyebabkan kerusakan fisik atau barang orang lain. Sehingga secara gampang buclaya kekerasan clapat diartikan sebagai suatu cara atau kebiasaan yang sudah lama acla clan akan tetap ada, cliakukan secara saclar clan melalui pertimbangan untuk melakukan tinclakan kekerasan clalam usahanya untuk memperoleh tujuan yang cliinginkan.

Mencermati definisi-definisi cliatas, kemudian yang mengsik aclalah pertanyaan apakah kekerasan sudah menjadi cliskursus yang termasuk clalam kategori budaya Bangsa Inclonesia, ini perlu dicemati karena bisa menjadi pukulan telak yang teramat menyakitkan bagi Bangsa Indonesia yang sudah terkenal memiliki adat ketimuran yang terkenal penducluknya selalu mengedepankan ketinggian etika, keramah-tamahan, kesopanan clan saling menghomati clalam pergaulan humanisnya clengan sesama manusia tanpa memperhatikan kebangsaan, agama clan bloodshipnya.

\section{Wacana Kekerasain di Indonesia}

Kalau kita mencermati wacana kekerasan yang terjacli di Indonesia, tampaknya suclah terjadi semenjak nenek moyang kita ada, bagaimana ceritacerita yang bisa kita clapati clalam literatur-literatur sejarah seperti perebutan kekuasalan pacla masa kerajaan-kerajaan Hinclu-Buclha di Inclonesia, bagaimana claya upaya clan siasat licik yang dilakukan Ken Arok untuk merebut kekuasaan clari Kerajaan Tumapel yang dipimpin oleh Tunggul Ametung calam usaha untuk memperoleh kekuasaan yang lebih besar dengan berdirinya Kerajaan Singasari, bagaimana kekerasan clan tinclakan represif yang dilakukan oleh kerajaan-kerajaan clahulu clalam upaya menarik pajak clari rakyatnya.

Pada masa kolonial Belanda clan Jepang, tidak bisa dipungkiri pada masa ini Bangsa Indonesia mengalami penderitaan yang luar biasa atas perlakuan pemerintahan kolonial, penindasan, pemerasan, pemaksaan, exploitation de l'thomepar l'bome, eksploitasi manusia oleh manusia: dan lain sebagainya. Terlebih lagi ketika diundangkannya Tanam Paksa dan kerja paksa, Rodi clan Romusha, berapa banyak nyawa yang melayang, betapa keji perlakuan mereka clan alangkah bejat moral mereka.

Pacla masa awal pemerintahan Indonesia di bawah Presiden Soekarno, kekerasan yang paling menonjol adalah kekerasan yang dilakukan oleh Partai Komunis, yang mengklaim clirinya sebagai partai anti Tuhan dan mempropagandakan bahwa agama aclalah canclu bagi masyarakat, mengikut kepada pendirinya Karl Marx (1818-1883) dan Frederick Engels (1820-1895) dalam Communist Manifesto mereka(1848) (John Lyclen, 1995 : 26). Klaim politik ini jelas membahayakan bagi Bangsa Indonesia yang ber-Ketuhanan Yang Maha Esa clan mendapat tantangan keras clari para Ulama clan santri. Pertentangan inilah yang memicu timbulnya kekerasan dan kekejaman antara rival politiknya, hingga. terjadi pembantaian massa clan penyembelihan massal yang clilakukan keclua belah pilak.

Kemudian pacla masa Orcle Baru atau Orcle Rezim Soeharto, mungkin ada manfaarnya apabila kita melihat asal muasalnya, Orde Barụ aslinya diciptakan oleh Hitler beserta Partai Nazinya yang clisebutnya sebagai Orde Baru Eropa yang kemudian dimetaforfosis oleh Jepang menjadi sebuah icleologi Orde Baru Asia Timur Raya yang fasis. Kemudian apakah Orcle Baru Inclonesia juga berwatak fasis, ya memang fasis, ekstrem kanan, Labir dari kekerasan dan berakbir dalam kekerasan. Orde Soeharto 
menjalankan pemerintahannya dengan dan oleh ancaman, kekerasaan, paksaan, penggusuran, teror, fitnah, vonis tanpa proses, pemenjaráan sesuka tafsir penguasa, siksaan, pukulan, hantaman, penyetruman terhadap terdakwa, penculikan, penghilangan, pembunuhan clan lain sebagainya (Mangun Wijaya, $1998: 55)$.

Kekerasan pada masa Orde Soeharto ditampilkan clengan kemasan yang indah, semua atas nama negara, pembangunan dan nasionalisme. Rakyat yang tidak mendukung pembangunan, disingkirkan, dibunul, dihilangkan, diculik clan dicap $\mathrm{PKI}$, di mana pada waktu itu seseorang yang mendapat label PKI atau OT (Organisasi Terlarang) jangan berharap untuk dapat hidup clengan mudah apalagi kalau sudah menyangkut urusan birokrasi pemerintahan, meski dalam pemerintahan yang paling renclah yaitu Pemerintahan Desa.

Padla masa Pemêrintahan Abdurrahman Wahid, apabila kita mengikuti informasi media cetak maupun elektronik didukung dengan semakin bebasnya media clalam menyampaikan berita, kita clapat melihat berbagai kekerasan atau kerusuhan di berbagai pelosok Tanah Air Inclonesia, apakah itu permasalahan SARA, disintegrasi bangsa, penyerobotan tanah maupun permasalahan pelanggaran hak, tetapi perbedaannya dengan ordeorde sebelumnya adalah bahwa kekerasan-kekerasan dan kerusuhan-kerusuhan tersebut tidak dilakukan oleh penguasa atau atas nama kekuasaan, tetapi lebih dikarenakan adanya ketidakpuasan masyarakat.

\section{Usaha Pemetaan Masalah}

Kekerasan-kekerasan yang terjadi pada masa Pemerintahan Abclurrahman Wahid, baik yang bernuansa Suku, Agama, Ras clan Antar Golongan (SARA) maupun yang bernuansa disintegrasi bangsa tidak bisa dilihat dari siși lahiriyah saja, tetapi kekerasan-kekerasan tersebut perlu dikaji secara mendalam dari berbagai aśpek yang melingkupinya, karena naiknya Abdurrahman Wahid sebagai presiden merupakan suatu kompromi nasional yang tercermin clalam susunan kabinetnya yang berusaha mewadahi aspirasi dari semua kontestan politik yang ikut pemilu, sehingga kabinet tersebut dinamakan kabinet "Persatuan Nasional". Hal ini berimbas kepada munculnya dualisme kepemimpinan dari para menteri kabinetnya, dalam kondisi tertentu kepada parpolnya dan dalam kondisi yang lain kepada Presiden. Dan yang lebih memperparah, naiknya Abdurrahman Wahid mewarisi kondisi 'kiamat' dalam segala bidangnya sebagai warisan rezim Orde Baru di bawah pimpinan Jendral Soeharto.

Dalam tulisan ini penulis akan mengkaji kekerasan-kekerasan yang terjadi pacla masa Pemerintahan Abclurrahman Wahid clari berbagai aspek.

\section{Kajian Sosial-Politis \\ 1. Teori Desa Mengepung Kota}

Telah clisampaikan di muka bahwa naiknya Abdurrahman Wahid menjadi Presiden Inclonesia keempat adalah merupakan hasil kompromi nasional. Para penclukung bagi naiknya beliau menjadi presiden clari poros tengah dan golkar tidak secara tulus mendukungnya, tetapi sekedar "akboffu dhararain". Dengan ditolaknya pidato pertanggungjawaban Presiden Habibie yang merupakan kandiclat presiden clari Partai Golkar dan didukung Poros Tengah, tinggal dua kandidat presiden yaitu Abdurrahman Wahid dan Megawati Soekarno Putri yang sama-sama mempunyai 'cacat' dalam perspektif poros tengah dan Golkar. Kedua kandidat tersebut sama-sama merupakan pilihan sulit bagi mereka, tetapi akhirnya Gus Dur yang dipilih, karena menurut mereka Gusdur lebih tidak membahayakan dari Mega.

Keticlakpuasan ini yang memicu kedua kelompok tersebut untuk selalu mengkritik kebijakan-kebijakan Presiden dengan kritik-kritik yang seringkali tidak konstruktif, membangun bangsa dan negara, sehingga yang tampak dipemukaan roda pemerintahan yang dijalankan Presiden tampak 
amburadul dan kacau balau, karena yang ada dalam benak kedua kelompok tersebut hanya sisi-sisinegatif Presiden dan atau kebijakannyal, paclahal tidlak sedikit capaian kemajuan-kemajuan yang telah cliraihnya, baik dailam bidang ekonomi, sosial dan politik.

Munculnya berbagai kerusuhan dan kekerasan di berbagi pelosok Tanah Air barangkali juga merupakan imbas dari ketidakpuasian tersebut, sehingga tidaklah menyimpang jatuh apa yang disinyalir Menteri Pertahanan Kabinet Gus Dur, Juwono Soedarsono ketika berbicara pada seminar "Indonesian Economy, Half Full or Half Empty" yang diselenggarakan oleh Danareksa Research Institute di Jakaltal pada Kamis 6:Juli 2000, Beliau mengatakan bahwa ada dugaan kuat kroni mantan Presiden Soeharto berkepentingan dalam menciptakan kekacauan di Tanah Air, setiap pengusutan terhadap perkara korupsi kolusi dan nepotisme (KKN) di masa lampau pada akhirnya akan mengarah kepada mereka (Kompas, 7 Juli 2000). Begitu pula yang dikatakan Jaksa Agung Marzuki Darusman bahwa setiap kali Kejaksalan Agung memeriksa orang-orang clekat mantan Presiden Soeharto, maka eskalasi kerusuhan di daerah juga meningkatt.

Berbagai kerusuhan dan kekerasan yang diciptakan cli claerah-claerah ini pada akhirnya jugal merupakan usaha untuk menggoyang Pemerintahan Pusat di Jakarta dengan teori desa mengepung kota. Dengan meningkatnya eskalasi kerusuhan di daerah ini diharapkan oleh para provokatornya akan menyedot perhatian pemerintahan pusat untuk segera menurunkan segenap kekuatannya dan semua perhatiannya ke daerah, sehingga permaslahan utama yang dihadapi Bangsa Indonesia, ekonomi dan supremasi hukum tidak bisa dilaksanakan, sehingga para koruptor kakap bisa berlenggang kangkung kembali dan kondisi Bangsa Indonesia tampak seperti akan kiamat. Hal ini memudahkan bagi para rival politik Gus Dur untuk mengimpeacbmentnya dengan menyulap Sidang Tahunan MPR mendatang menjadi Sidang Istimewa. Melihat kondisi ini, maka tidak terlalu aneh kalau Gus Dur dalam setiap kunjungannya ke berbagai daerah kerusuhan selalu menekankan penyelesaiannya dari dan oleh mereka sendiri, pemerintah hanya sekedar memeberikan fasilitas kepalda mereka baik di Maluku maupun di Aceh, karena mereka sendirilah y'ang tahu dengan sebenarnyal akar permasalahan yang memicu terjadinya kerusuhan tersebut.

\section{Fundamentalisme Agama}

Meningkatnya eskalasi kekerasan pada dasawarsa terakhir di Indonesia, khususnya kekerasan yang "mengatasnamakan agama" kurang lebih dikarenakan pemahaman kaku umat terhadap agama. Gagasan yang mendasarinya adalah bahwa iman harus dipegang teguh secara penuh dan harfiah, tidak mengenal kompromi, keluwesan, reinterpretasi ataupun pengurangan (Gellner, 1994：13). Pandangan ini menempatkan doktrin sebagai "segaliagalanya" clan mengesampingkan aspek ritual dan etika sosial, ini berakibat pada gerakan clan misi yang dibawanya, menjadi formalistis, skripturalis dan fundamentalis yang berpandangan bahwa doktrin perlu ditetapkan secara persis dan sebàgai hal yang paripurna.

Padla masa Pemerintahan Abdurrahman Wahid, tidak sedikit kerusuhan dan kekerasan yang kurang lebih berlatar belakang fundamentalisme agama, kasus maluku, konflik antar agama yang terjadi 18 bulan lalu yang telah memakan korban sebanyak kurang lebih 4.000 jiwa, operasi dan penyerbuan sepihak atas tempat lokalisasi, tempat mesum dan diskotik oleh ormas-ormas Islam. Kasus kekerasan dengan modus operandi baru ad alah peristiwa penyerbuan attas Kampung Hanja, Cibuntiris clan Sindang Jaya Kecamatan Bojonggambir Kabupaten Tasikmallaya pada 21-24 Juni 2000 yang berakibat 30. buah rumah habis terbakar. Penyerbuan ini clilakukan oleh orang-orang bertopeng dengan alasan daerah-daerah tersebut merupakan sumber dan berkembangnya aliran sesat. Penyerbuan ini jelas bertentangan dengan pasal 29 ayat 2 UUU 1945 dan Universal Declaration of Human Right antikel ke-18 
tentang kebebasan beragama.

Dalam teori-teori ilmu sosial, menurut Moeslim Abclurrahman (1995 : 298) bahwa agama selain menjadi pemersatu sosial juga dapat menjadi unsur konflik, clua unsur tersebut pada clasarnya merupakan clua sisi mata uang yang mempnyai kekuatan sama clalam proses kohesi dan konsensus. Wajah ganda clari suatu agama sebagai iclentitas kohesi umat seagama pada waktu yang bersamaan akan menghasilkan potensi konflik dengan umat agama lainnya. Sehubungan clengan tesis ini, konflik antar kelompok agama akan menjadi suatu yang rawan, karena apabila kita clapat mengatur konflik tersebut agar ticlak mengarah clan tidak terjebak ke clalam persaingan ekonomi, kekuasaan, kepentingan dan lain sebagainya, maka kita clapat memodifikasi clan merekayasa hubungan antar agama clan clengan negara tersebut menjadi hubungan yang mutualistis dan kontributif.

\section{Belum tegaknya Supremasi Hukum}

Hukum merupakan seperangkat aturan yang berfungsi mengatur tingkahlaku manusia clalam hiclup bernegara clan bermasyarakat. Idealnya suatu aturan hukum harus ada terlebih clahulu clari pada perbuatan yang akan cliatur, karena fungsi hukum adalah mengatur, tetapi fakta berbicara bahwa aturan hukum sering tertingal jauh clari perbuatan-perbutan "melawan hukum". Kondisi ini berakibat perbuatanperbuatan tersebut ticlak bisa clijerat dengan aturan hukum yang catang kemudian, karena prinsip hukum adalah tidak berlaku surut. Ini sejalan dengan Firman Allah "Wa ma kumna mu adzibiina batta nab'atsa rasula"

Selanjutnya suatu aturan hukum akan menclapat posisi tinggi, dihormati dan mendapat supremasi di masyarakat clan negara apabila semua aparat pejabat hukum (laur enforcement officer) bertindak secara konsekuen, netral dan tegas dalam menerapkan hukum, ticlak membedakan antara yang "kecil" clan "besar" clan ticlak memihak kepada yang lebih menguntungkan. Namun dalam prakteknya hukum clan para aparat penegaknya di Indonesia masih kelihatan memiliak clan memperhatikan status -yang pacla pemerintahan sekarang masih cliusahakan untuk bersikap netral--. Kondisi inilah yang menyebabkan eskalasi keticlakpuasan dan keticlakpercayaan masyarakat terhadap hukum memuncak yang pada akhirnya ditumpahkan kepada tindakan-tindakan yang main hakim sencliri.

\section{Suatu Upaya Solusi}

\section{Kajian Agama}

Kajian ini lebih clifokuskan kepada Islam karena basis agama penulis adalah Islam clan sangat tidak pantas apabila membahas clari sisi Kristen, misalnyal, clisamping penulis tidak mempunyai otoritas, juga sama sekali ticlak mempunyai kapabilitas untuk mengkaji Agama Kristen yang juga mempunyai sisisisi filosofis clan metafisis di clalam ajaran-ajarannya. Kajian agama non-Islam biarlah dikaji oleh mereka yang mempunyai otoritas dan kapabilitas dalam biclang tersebut. Kajian ini lebih ditekankan untuk mengkritisi kekerasan yang mengatasnamakan agama atau agama dijadikan alat legitimator untuk melakukan tinclak kekerasan, tinclakan represif clan pembunuhan bahkan pembantaian terhadap warga non-Islam.

Islam berasal dari akar kata "salima" yang clalam kamus Hans Wehr, diantaranya diartikan sebagai "to be safe and sound, unbarmed dan secure" kemudian menclapat tambahan huruf alifdi clepannya, menjadi aslama yang bentuk mashdamya adalah islam yang diantarnya cliartikan sebagai "to band over, to turm over, to surrender dan to declare oneself comitted to the uill of God.Dari akar kata "salima" tersebut bisa dipahami bahwa umat Islam harus lebih mementingkan kesejahteraan, kedamaian, perlinclungan dan tidak melakukan tinclakan yang dapat membahayakan diri sendiri atau orang lain. Seclangkan clari kata "Aslama" clapat dipahami bahwa Umat Islam harus lebih mengeclepankan penyerahan cliri kepada Allah secara sungguh-sungguh, karena seseorang yang telah mengaku dirinya muslim berarti 
telah mengakui bahwa semua yang diperbuatnya adalah atas kehendak Allah, "La baula wa laa quwwara illa billabial Aliyyial Adziim", tidak dengan mengedepankan emosi sesat yang bisa merugikan diri sendiri dan orang lain. Pengakuan ini akan tidak berarti apabila tidak direfleksikan dalam kehidupan sehari-hari.

Daric definisi di atas kita perlu memahami agama tidak hanyal pemahaman vialistis, yang tampak di permukaan saja, tetapi harus melalui pemahaman dan kontemplasi yang mendalam. Di sini penulis akan mengemukakan metode pemahaman agama yang barangkali perlu kita cermati.

\section{Islam Agama Etika}

Islam sangat mengedepankan etika, Rasulullah, sebagaimana yang diungkapkan oleh Sayyidah Aisyah "Kana kbulluqubu al Quran". Di sini bisa dipaliämi bahwa Qur'an sudah menyatu dalam diri Rasulullah yang terefleksikan dalam kesehariannya. Nash-nash Qur'an terutama yang berkaitan clengan etika secara otomatis membias pada tindaktanduknya dalam kehidupan bermasayarakat dan ber"negara". Penekanan Rasulullah atas pentingnya menjunjung etika ini tercermin dalam sabdanya "Innama bu'itstu li utammima makarim al akblaq". Dalam hadits ini clapat dipahami bahwa misi Rasulullah dalam dakwahnya tidak sekedar untuk memerintahkan umatnya untuk mengedepankan etika, tetapi lebih dari itu berusaha menyempurnakan etika yang sudah tinggi dengan senantiasa membiasakan berakhlak yang mulia dalam kehidupan keseharian dalam bermuamalab antara sesama.

Sehingga tidaklah berlebihan apabila seorang pembaharu pemikiran Mesir, Al Tahtawi (1801-1873) mengatakan bahwa untuk mencapai kehiclupan yang sejahtera semua masyarakat harus berpegang teguh kepada agama dan budi pekerti yang baik (Nasution, 1996 : 47). Dalam memberikan komentar terhadap faham Ibnu Taimiyah yang membagi ajaran-ajaran Islam dalam dua kategori, ibadat dan Mucamalab,
Muhammad Abcluh mengatakan bahwa ajarann-ajaran yang terdapat dalam Qur'an maupun hadits mengenai ibadat bersifat tegas, jelas dan terperinci. Sebaliknya ajaran-ajaran (baca : etika) mengenai keliclupan kemasyarakatan umat hanya merupakan clasar-dasar dan bersifat umum dan jumlahnya hanya sedikit sehingga dapat dan perlu disesuaikan dengan zaman, tempat dan kondisi sosial, "al Islamu shalibuin fi kulli zaman wa makan" (Nasution, 1996 : 63-64).

\section{Islam Agama Perdamaian}

Islam adalah seperti dua sisi mata uang, satu sisi berisi ajaran-ajaran kebenaran sedangkan sisi yang lain mengedepankan wajah Islam yang santun, kasil clan menyejukkan bagi semua umat manusia, termasuk makhluk lainnya yang ada di muka bumi. Keclua sisi ini merupakan satu kesatuan yang saling melengkapi dan menguatkan, apabila salah satu sisinya hilang maka 'uang' itu tidak sempurna, untuk tidak mengatakan tidak ada nilainya sama sekali. Barangkali hadits yang diriwayatkan Imam Muslim dari Abu Hurairah ini cukup untuk dijadikan referensi, "Qiila ya Rasulallab Ud"u "ala al Musyrikiina Qaala : Inni lam Ubats La'a aanan wa Innama Bu'itstu Rabmatan" (Ada seseorang memolon kepada Rasulullah : "Wahai Rasulullah kecamlah orang-orang musyrik tersebut". Rasulullah menjawab : "Sayat tidak diutus sebagai pelaknat, tetapi saya diutus hanyal untuk memberi kasilh dan salyang".

Islam adalah agama misi, begitu juga agamaagama yang lain, agama yang memerintallakan kepada umatnya untuk mengabarkan ajaran-ajarannya kepada orang lain. Dalam hal ini Islam menetapkan aturan-aturan seperti Firman Allah "La ikraaba fi ad diin ...", ayat ini diturunkan karena kebiasaan wanita. Anshar, apabila mereka mempunyai anak, mereka akan meyahudikan anak-anak mereka (sebagaimana kebiasaan wanita-wanita Jahiliyah). Ketika Bani Nadzir (Yahudi) diusir dari perkampungan mereka dimana diantara mereka ada golongan Anshar (Islam), ayal-ayah mereka mengatakan : "Kita tidak akan membiarkan anak-anak kita (untuk memeluk 
Agama Yahudi)" (Qardhawi, 1994 : 43)

Sebagai agama misi, dalam mengabarkan ajaranajarannyal, kita perlu mencontoh metodologi yang digunakan Rasulullah, diantaranyal sebagaimana yang diungkapkan dalam Surat Ali Imran : 159 "Fa bima rabmatin min Allabi linta labum walau kunta fadzdzan gbalidz al qalbi lanfadzdzu min baulik". Menurut as-Suyuthi (1994 : 71) bahwa sifat kasih sayang clan tidak kasar dan keras hati yang dikedepankan Rasulullah clalam hidup bermasyarakat adalah semata rahmiat Allah yang agung. Seclangkan menurut Imam Abdurral hman as-Suyuthi (1993 : 358) maksud ayat ini adalah Allah membersilhkan pada diri dan hati Rasulullah sifat keras kepala dan keras hati clan menjadikan Rasulullah sebagai hamba yang karib, pengasih dan penyayang terhadap orang mu'min clan juga terhadap orang musyrik sebagaimana hadits di atas. Pendapat ini juga didukung hadits yang diriwayatkan Imam Ahmad "Yaumaidzin lata'lamu yabudu anna fi diinina fusbatun inni ursiltu bibanifipatin sambatin" ( pada hari itu Orang Yahudi benar-benar mengetahui bahwa agama kami membahas masalah yang komprehensif. Sesungguhnyal saya cliutus untuk mengabarkan agama yang penuh toleransi). Kalau kita perhatikan ayat-ayat dan hadits-hadits di atas, betapa Islam mengandung ajaran-ajaran yang sangat humanis, penuh kasih dan sayang terhadap sesama tanpa memperhatikian agama, etnis dan golongan. "La fadbla li Arabiyyjin walaa A'jamijy)in illa bi atTaqua".

\section{DAFTAR PUSTAKA}

A S Hornby, Oxford Advanced Leaner's Dictionary of Current English, New York, Oxford University Press, cet. Ke-23, 1986

As-Suyuthi, Shofwab al-Bayan li Ma'aanial-Qur'an al-Karim Mudzayyilan bi Asbab an-Nuzul, Kairo, Dar as-Salam

CD Islamic studies' Software, mausu'ab al-Hadits asSyarif al-Kuttub al-Tis'ab.
Ernest Gellner, Menolak Posmodernisme Antara Fundamentalisme Rasional dan Fundamentalisme Religius, Hendro Prasetyo dan Nurul Agustina (penterjemah), Bandung, Mizan, 1994

Hans Wehr, A Dictionary of Modern Written Arabic, Ithaca New York, Spoken Language Service Inc., 1976

Harun Nasution, Pembaharuan Dalam Islam Sejarah Pemikiran clan Gerakan, Jakarta Bulan Bintang, 1996

Imam Abclurrahman ibn al-Kamal Jalaluddin alSuyuthi, Tafsir ad-Dur al-Mantsurfi at-TafsiralMa'tsur(juz:2), Lebanon, Dar el Fikr, 1993

Karl Marx and Frederick Engels, Religion is Opium of The People, dalam Enduring Issues in Religion, John Lyden (editor), San Diego, Greenhaven Press Inc., 1995

Moeslim Abclurrahman, Islam Transformatif, Jakarta, Pustakan Firdaus, 1995

Soerjono Soekanto, Sosiologi Suatu Pengantar, Jakarta, Yayasan Penerbit Universitas Indonesia, cet. Ke-3, 1974

Tim Penyusun Kamus Pusat Pembinaan dan Pengembangan Bahasa, Kamus Besar Babasa Indonesia, Jakarta, Balai Pustakal, cet. Ke-7, 1996 Yusuf Qardhawi, Minoritas Non Muslim di Dalam Masyarakat Islam, (Terjemah), Bandung, Karisma, 1994

Y.B. Mangun Wijaya, Menuju Republik Indonesia Serikat, Jakarta, PT. Gramedial Pustaka Utama, 1998 